\title{
PALINOFÁCIES E EVOLUÇÃO QUATERNÁRIA DO RIBEIRÃO DA MATA, MUNICÍPIO DE VESPASIANO, MG, BRASIL
}

\author{
KARIN ELISE BOHNS MEYER \\ Instituto de Geociências, Centro de Pesquisa Manoel Teixeira da Costa, UFMG, Av. Antônio Carlos, 6627, 31270-901, \\ Belo Horizonte, MG, Brasil.bohnsmeyer@yahoo.com.br
}

\author{
ALLAN BÜCHI, JOACHIM KARFUNKEL \\ Instituto de Geociências, Departamento de Geologia, UFMG, Av. Antônio Carlos, 6627, 31270-901, Belo Horizonte, \\ MG, Brasil.allanbuchi@gmail.com, jkarfunkel@yahoo.com
}

MONIKA HOFMANN \& ANDREAS HOPPE

Institut für Angewandte Geowissenschaften, Technische Universität Darmstadt, Schnittspahnstrasse, 9, 64289, Darmstadt, Alemanha.mb.hofmann@gmx.de,ahoppe@geo.tu-darmstadt.de

\begin{abstract}
PALYNOFACIES AND QUATERNARY EVOLUTION OF RIBEIRÃO DA MATA, VESPASIANO CITY, MG, BRAZIL. This study presents two palynofacies associated with floodplains of Ribeirão da Mata, a river in the northwest of the municipality of Vespasiano, Minas Gerais State, southearstern Brazil. In these fluvial deposits, ten profiles designated as $\mathrm{P} 1$ to $\mathrm{P} 10$, as well as $\mathrm{C}^{14}$ dating, were determined. The $\mathrm{C}^{14}$ method yielded ages between 7,258 and 4,956 years BP for the thicker deposits of the floodplains. The profiles exhibited the following sedimentary sequence. At the base, coarse sand was found with small cross bedding, indicating deposition in fluvial channels. This facies is overlain by packages of clay containing silt and fine sand, parallel laminations representing deposits in floodplains. Toward the top, there are coarser sediments characterizing paleochannels often with indication of paleocurrents in different directions. The youngest topmost facies is a package of silt and fine sand with ferruginous concretions related to a more recent fluvial system. The identification of the organic components yielded two palynofacies, designated here as A and B, that indicate different subenvironments within the floodplain. The samples RM-04 and RM-06 of palynofacies A revealed $60 \%$ amorphous organic material (AOM), about $20 \%$ opaque biostructured phytoclasts and less than $10 \%$ non-opaque phytoclasts characterizing areas of deeper water, whereas desoxic-anoxic pertain to the shallow floodplains. This palynofacies represents at profile P6 the sediments deposited between 7,258 and 5,529 years BP. In contrast the samples RM-01, RM-02 and RM05 revealed opaque biostructured phytoclasts (36-50\%) and AOM, and/or non-opaque phytoclasts, besides fungal spores. Palynofacies B in profile P5 represents a depositional environment of areas bordering a floodplain and indicates an age of 5,529 years BP for the deposits in this floodplain.
\end{abstract}

Key words: palynofacies, Holocene, Ribeirão da Mata, Minas Gerais State, Brazil.

RESUMO - Este trabalho apresenta a caracterização de duas palinofácies associadas à planície de inundação dos depósitos fluviais quaternários do ribeirão da Mata, município de Vespasiano (MG). Foram realizados dez perfis estratigráficos em tais depósitos fluviais, designados com os códigos P1 a P10 e datações pelo método de $\mathrm{C}^{14}$. Estas datações evidenciaram que os depósitos mais espessos da planície de inundação ocorreram entre 7.258 e 4.956 anos A.P. Os perfis mostraram seções sedimentares constituídas pela sucessão das seguintes fácies: na base, areia grossa com estratificação cruzada, caracterizando os depósitos do canal fluvial, que, são sobrepostas por pacotes de argila com laminações plano-paralelas de silte e areia fina, associadas aos depósitos de planície de inundação; acima desta, sedimentos mais grossos caracterizando paleocanais com indicações de paleocorrentes em diversas direções, e, no topo, pacotes de silte a areia fina com concreções ferruginosas, relacionadas ao sistema fluvial mais recente. A partir da identificação dos componentes orgânicos particulados foram caracterizadas duas palinofácies, A e B. A palinofácies A (amostras RM-04 e RM-06), com percentuais em torno de 60 \% de matéria orgânica amorfa (MOA), fitoclastos opacos bioestruturados (20\%) e fitoclastos não-opacos (8\%), caracteriza as regiões com lâmina de água mais profunda, e, disóxicas-anóxicas da paleoplanície de inundação. Esta palinofácies é representativa dos sedimentos depositados entre 7.258 e 5.529 anos A.P., no perfil P6. Já a palinofácies B (amostras RM-01, RM02 e RM-05) mostrou fitoclastos opacos bioestruturados (36-50\%), e MOA e/ou fitoclastos não-opacos perfurados, além de esporos de fungo. A palinofácies B representa o ambiente deposicional das áreas de borda da planície de inundação e no perfil P5 foi depositada há, aproximadamente, 5.529 anos A.P.

Palavras-chave: palinofácies, Holoceno, ribeirão da Mata, Minas Gerais. 


\section{INTRODUÇÃO}

As variações paleoclimáticas e a neotectônica são fatores que influenciam a evolução dos ambientes deposicionais continentais quaternários no Estado de Minas Gerais, com reflexos significativos sobre a disposição das fácies sedimentares, como por exemplo, as que caracterizam os depósitos fluviais quaternários do ribeirão da Mata. Neste contexto, eventos como o deslocamento da área da planície de inundação, do paleocanal fluvial, entre outros, podem ser identificados, através de diferentes palinofácies, pela deposição de conjuntos distintos de palinomorfos e matéria orgânica particulada (Traverse, 1994).

A caracterização qualitativa e quantitativa da matéria orgânica particulada contida nos sedimentos e nas rochas sedimentares constitui a análise de palinofácies. Esta técnica visa à identificação dos componentes particulados individuais, a determinação de suas proporções relativas e absolutas, incluindo suas dimensões e seu estado de preservação (Tyson, 1995).

A aplicação da análise de palinofácies em estudos paleoambientais se baseia no fato de que a deposição de diferentes conjuntos de componentes orgânicos particulados é reflexo dos fatores que atuam na deposição das partículas orgânicas e dos sedimentos nos diferentes ambientes deposicionais. Estudos visando o entendimento da distribuição da matéria orgânica particulada em ambientes deposicionais fluviais, principalmente nas áreas deltaicas, são bem conhecidos (e.g. Hart, 1986; Lenoir \& Hart, 1988; Lorente, 1990). No entanto, pouco se sabe sobre a caracterização dos parâmetros de palinofácies em depósitos fluviais continentais quaternários no Brasil e que evoluíram sob in- fluência das mudanças paleoclimáticas e neotectônicas.

O objetivo deste trabalho consiste na caracterização da matéria orgânica particulada contida em amostras selecionadas de dez perfis sedimentares (P1 a P10) visando à identificação das condições de deposição das áreas de planície de inundação durante a evolução holocênica do depósito fluvial do ribeirão da Mata, município de Vespasiano (MG).

\section{CONTEXTO GEOLÓGICO E ESTRATIGRÁFICO}

\section{Geologia regional}

A área de estudo se insere na borda sudeste do Cráton São Francisco, entidade tectônica do Ciclo Brasiliano (Almeida, 1977), uma das porções da Plataforma Sul-americana que não foram envolvidas nos processos orogênicos durante o Neoproterozóico (Alkmim \& Martins-Neto, 2001). A tectônica regional, de caráter compressivo, imprimiu estruturas secundárias (foliação $S_{1}$ ) paralelas às estruturas primárias (acamamento $\mathrm{S}_{0}$ ). Indicadores cinemáticos demonstram transporte tectônico de leste para oeste. A paragênese mineral indica metamorfismo na fácies xisto-verde baixo. Sobre esse compartimento, três unidades pré-cambrianas se destacam localmente: o embasamento granito-gnáissico do Complexo Belo Horizonte, seguido pela sequência vulcanossedimentar arqueana do Quadrilátero Ferrífero e pelos sedimentos neoproterozóicos do Grupo Bambuí (Figura 1).

No embasamento o litotipo predominante é um gnaisse cinza-claro, frequentemente exibindo bandamento composicional e feições de migmatização. Noce et al. (1997) designaram este litotipo como Gnaisse Belo Horizonte e apon-

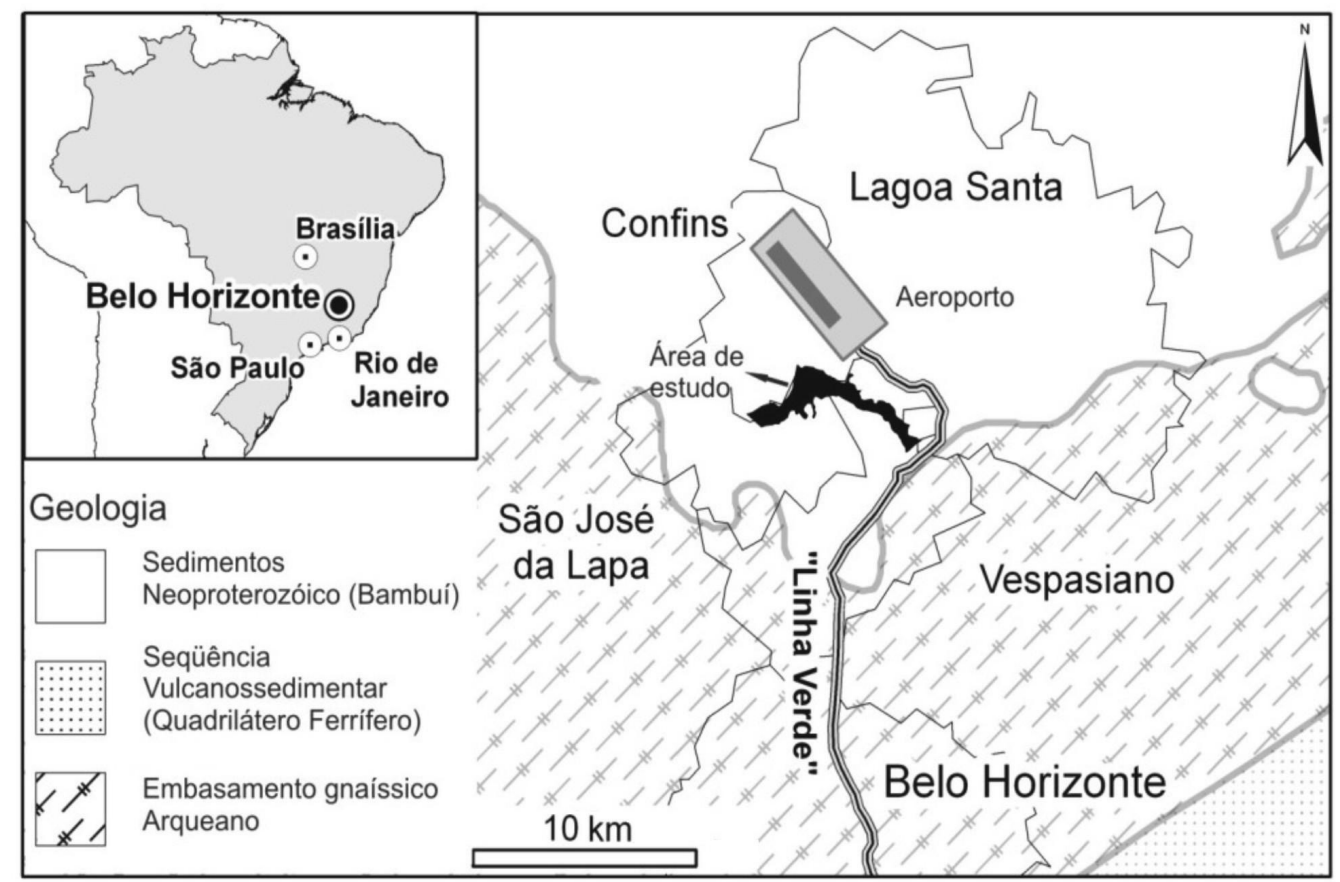

Figura 1. Mapa de localização do ribeirão da Mata, Município de Vespasiano, Minas Gerais, Brasil (modificado de Hofmann et al., 2009).

Figure 1. Location map of Ribeirão da Mata, Vespasiano City, Minas Gerais State, Brazil (modified from Hofmann et al., 2009). 
taram um caráter ortoderivado. A morfologia dos terrenos se caracteriza por morros arredondados com cobertura de mata densa e os afloramentos são constituídos de rocha alterada com poucas ocorrências de rochas sãs.

A sequência metavulcanossedimentar arqueana do Supergrupo Rio das Velhas corresponde à associação de litofácies plutônica-vulcânica, máfica-ultramáfica e sedimentar, e é constituída principalmente de xisto verde metassedimentar, englobando sedimentos pelíticos e psamíticos, e filitos com intercalações de quartzito, dolomito, metaconglomerados e formação ferrífera (Dorr, 1969).

Os sedimentos neoproterozóicos do Grupo Bambuí são representados localmente pelas formações Sete Lagoas e Serra de Santa Helena, e constituem uma sequência de rochas carbonáticas (metacalcários com diferenetes granulometrias e metapelitos) alternadas com terrígenos, depositadas num ambiente de sedimentação exclusivamente marinho. Neste contexto, a Formação Sete Lagoas é constituída predominantemente por metacalcarenitos e metacalcilutitos, com características de retrabalhamento. Já na Formação Serra de Santa Helena, o predomínio de metapelitos representa uma sucessão monótona de ritmitos silto-argilosos cinzaesverdeados, com laminação planoparalela, apresentando marcas onduladas de pequeno porte (Schöll, 1976).

\section{Aspectos físicos e sedimentológicos}

O ribeirão da Mata é um afluente importante do rio das Velhas, bem como vetor de abastecimento na parcela norte da Região Metropolitana de Belo Horizonte, e vem sofrendo intensa mineração de argila, areia e cascalho desde a década de 1940, o que ocasiona inúmeros problemas ambientais. Está localizado no município mineiro de Vespasiano, nas proximidades do Aeroporto Internacional de Confins, entre a MG 010, Linha Verde, e a MG 424.

As feições fitogeográficas principais que ocorrem na região são a Mata Atlântica e o Cerrado. A vegetação local está diretamente influenciada pelos litotipos, sendo o clima e o relevo fatores determinantes também. Nos topos aplainados com solos rasos e ácidos, predomina vegetação típica de Cerrado. Sobre o embasamento granito-gnáissico, o fitotipo é composto de vegetação reliquiar primitiva. Nas regiões em que predominam os calcários do Grupo Bambuí a vegetação é típica da Mata Atlântica, mata do tipo mesófila que está alojada em dolinas, maciços e em outras feições cársticas.

$\mathrm{O}$ clima da região pode ser considerado do tipo AW, ou seja, tropical úmido, com duas estações definidas, inverno seco e verão chuvoso (Nimer, 1989). Os quatro tipos de solo característicos da região podem ser definidos essencialmente como residuais, representados pelos solos do embasamento, do metacalcarenito, do metapelito e dos depósitos aluvionares. Os depósitos aluvionares ao longo do ribeirão da Mata possuem granulometria variada de argila ao cascalho, sendo essencialmente, arenosos nos trechos onde o substrato rochoso é representado pelo embasamento, e, argiloso nos terrenos de metacalcário e metapelito.

A área em estudo apresenta uma variação considerável nas formas de relevo. Esta diversidade morfológica se deve aos processos atuantes nos vários tipos litológicos locais, observando a evolução de duas unidades de relevos estruturais; a faixa de cuestas (embasamento e metapelitos) e a zona de carste (Kohler, 1989). Outras feições geomorfológicas que se destacam são os terraços fluviais e as planícies de inundação. Estas planícies são as faixas inundadas e cobertas por sedimentos aluviais periodicamente depositados; já os terraços constituem antigas planícies de inundação abandonadas, caracterizados por planos de deposição horizontais situados em cotas acima da planície de inundação atual, e são delimitados por rebordos erosivos.

O aluvião do ribeirão da Mata é o principal depósito deste tipo da área, ocorre de forma irregular e ao longo do curso d'água. Nas porções mais altas estão caracterizados os depósitos mais antigos, constituídos de terraços de forma tabular e granulometria que varia de seixos a matacões. Entretanto, na planície aluvionar, os sedimentos estão distribuídos de maneira irregular, típica de ambiente fluvial meandrante. As estruturas principais são laminações planoparalelas, estratificações cruzadas acanaladas e paleocanais.

Os depósitos aluvionares são formados por sedimentos mal selecionados com granulometria que varia de argila a matacão. Estes, em estratos irregulares ocorrem em forma de lentes e camadas contínuas e descontínuas (Figura 2) como observado em trabalho de campo e na interpretação dos poços tubulares perfurados pela COPASA. Estes poços mostram que a espessura do aluvião do ribeirão da Mata varia de 8 a 40 m. Esta espessura é anômala levando em consideração o porte e gradiente hidráulico do ribeirão, o que sugere a ocorrência de movimentos geológicos recentes, que foi capaz produzir tamanha espessura nos depósitos do aluvião.

\section{A neotectônica quaternária}

Trabalhos sobre a ocorrência de eventos tectônicos recentes nas localidades em questão são escassos e ainda apresentam investigações preliminares. Karfunkel et al. (2006) perceberam a partir de análises de imagens de satélite que a largura atual do aluvião do ribeirão da Mata, localmente acima de $1.000 \mathrm{~m}$, em conjunto com seu gradiente hidráulico mínimo, entre a MG 424 e MG 010, não está em conformidade com o volume dos sedimentos nele depositado. A direção do fluxo do ribeirão (SE) está discordante, em relação aos outros tributários pertencentes à bacia do rio das Velhas, estes comportamentos anômalos foram alguns dos indícios observados, que impulsionaram a pesquisa sobre os movimentos tectônicos recentes que atuaram na região.

Analisando registros de movimentos rúpteis no campo, representados por falhas normais, Karfunkel et al. (2006) identificaram a existência de um gráben que foi denominado Gráben Vespasiano-Pedro Leopoldo que possui direção preferencial NW-SE. Essas falhas estão dispostas de maneira que as coberturas mais recentes, como por exemplo, a laterita, cascalheiras e colúvios encontram-se afetadas por esses movimentos gerando feições, como pequenos grábens e hosts.

Pagung et al. (2007) com o objetivo de avaliar se as 
stonelines descontínuas contidas nas lateritas reliquiares da superfície de aplainamento sul-americana, utilizaram o método geofísico Ground Penetrating Radar (GPR) para determinar variações laterais e/ou verticais bruscas, representado, assim direções de falhas. Os radargramas obtidos apresentaram um refletor descontínuo a aproximadamente $8 \mathrm{~m}$ de profundidade, cuja geometria e orientação (NW-SE) apontam como sendo uma falha normal, favorecendo a proposta da existência do Gráben Vespasiano-Pedro Leopoldo, confirmada depois em mapeamento detalhado efetuado por Büchi \& Pagung (2008).

\section{MATERIAL E MÉTODOS}

Dos dez perfis estratigráficos levantados ao longo do leito atual do ribeirão da Mata (P1 a P10), foram selecionadas cinco amostras sedimentares para o estudo de palinofácies (Figuras 1-2). O tratamento químico das amostras foi realizado no Laboratório de Palinologia do Centro de Pesquisa Manoel Teixeira da Costa, IGC/UFMG, de acordo com os procedimentos palinológicos não oxidantes descritos por Tyson (1995), Mendonça Filho (1999) e Mendonça Filho et al. (2002), que consistem, basicamente, no tratamento com ácido clorídrico e fluorídrico para eliminação da fração mineral e na separação e concentração da matéria orgânica do resíduo mineral com cloreto de zinco.

A fração maior que $6 \mu \mathrm{m}$ foi concentrada para a montagem de lâminas em gelatina glicerinada e Entellan. As lâminas foram depositadas na Palinoteca do Laboratório de Palinologia do Centro de Pesquisa Manoel Teixeira da Costa, IGC/UFMG sob a numeração MP-Pa 0068 a 0073.
A classificação da matéria orgânica particulada foi realizada em microscopia de luz branca transmitida sob aumentos de 250 e 400x. A intensidade relativa da fluorescência dos componentes da matéria orgânica foi avaliada com o uso de luz azul incidente no microscópio Olympus BX-51 do Laboratório de Palinologia do Centro de Pesquisa Manoel Teixeira da Costa, IGC/UFMG.

A contagem da M.O. particulada para análise de palinofácies considerou toda a matéria orgânica particulada até 500 partículas.

\section{Análise de palinofácies}

As adaptações da classificação proposta por Tyson (1995) adotadas neste trabalho foram sistematizadas nas publicações de Mendonça Filho et al. (2002) e Menezes et al. (2008), tendo sido adotadas em outros trabalhos de palinofácies no Brasil (e.g. Menezes, 2002; Meyer et al., 2005, 2006). Os componentes orgânicos particulados identificados podem ser vistos nas Figuras 3-4.

De acordo com esta classificação, a matéria orgânica particulada é referente a três grupos: palinomorfos, fitoclastos e matéria orgânica amorfa (MOA), e, cada um destes três grupos principais é subdividido de acordo com características como tamanho das partículas, estado de preservação, coloração, entre outros. Esta caracterização, o mais detalhada possível possibilita identificar caracteres relacionados ao estado de preservação, transporte e origem biológica dos componentes orgânicos particulados, dentre outros, permitindo inferências sobre as condições ambientais nos ambientes de sedimentação.

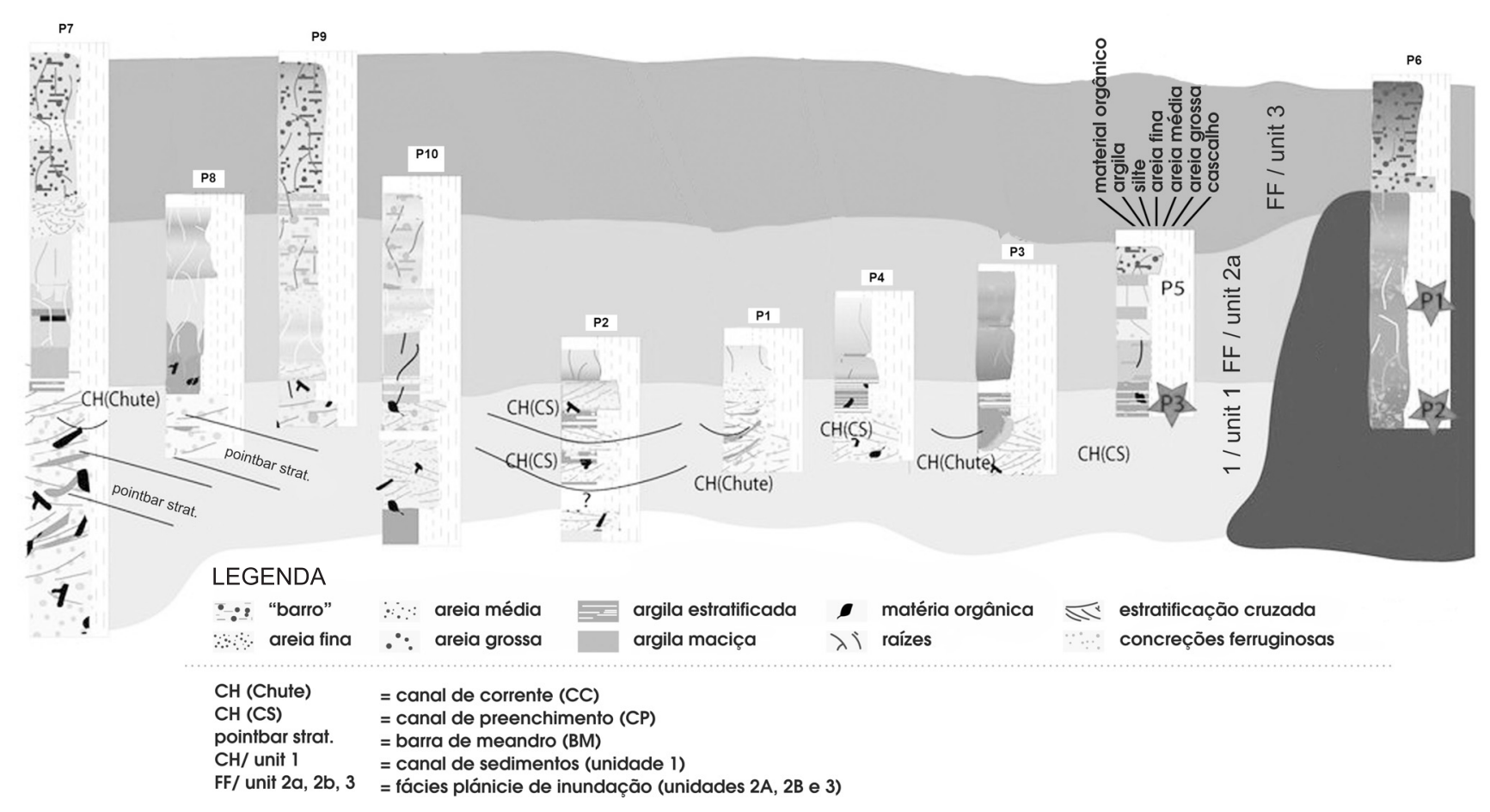

Figura 2. Perfis estratigráficos P1 a P10 (modificado de Hofmann et al., 2009).

Figure 2. Stratigraphic profiles P1 to P10 (modified from Hofmann et al., 2009). 


\section{RESULTADOS}

\section{Estratigrafia dos perfis P1 a P10}

As fácies sedimentares que caracterizam os perfis levantados ao longo do canal fluvial do ribeirão da Mata estão representadas na Figura 2. Os perfis mostram sequências sedimentares constituídas pela sucessão das seguintes fácies: na base, areia grossa com estratificação cruzada caracterizando os depósitos do canal fluvial, que é sobreposta por camadas de argila intercaladas por camadas de siltito e areia fina, associadas aos depósitos de planície de inundação; acima desta, sedimentos mais grossos que caracterizam paleocanais com indicações de paleocorrentes, e, no topo, pacotes de silte a areia fina com concreções ferruginosas, relacionadas ao sistema fluvial mais recente.

As sequências descritas acima representam um típico ambiente sedimentar fluvial (Suguio, 2003), no qual estruturas como laminações planoparalelas, estratificações cruzadas acanaladas e paleocanais são comuns. A planície aluvionar apresenta sedimentação irregular em camadas contínuas que são interrompidas frequentemente por lentes de material diverso. Estes depósitos aluvionares são formados por sedimentos mal selecionados com granulometria que varia de argila a seixo.

\section{Datações radiocarbônicas}

Datações radiocarbônicas foram realizadas pela técnica de espectrometria de acelerador de massa (AMS) no AMS C14-Labor Erlangen, Alemanha. Foram datadas três amostras sedimentares coletadas das fácies da planície de inundação (Figura 2) e que evidenciaram as idades de 7.258, 5.529 e 4.956 anos A.P.

\section{Características das palinofácies identificadas}

Os resultados da distribuição quantitativa e da caracterização dos grupos da matéria orgânica particulada nas amostras estudadas estão sintetizados na Figuras 3-4. Foi possível identificar duas palinofácies, denominadas A e B.

A palinofácies A, identificada nas amostras RM-04 e RM06, mostrou que a MOA foi o componente orgânico particulado mais significativo $(60 \%)$, os fitoclastos opacos bioestruturados (20\%) e os fitoclastos não-opacos (8\%) apareceram como componentes secundários. Esta palinofácies é representativa dos sedimentos depositados entre 7.258 e 5.529 anos A.P., no perfil P6.

Já a palinofácies B, caracterizada nas amostras RM-01, RM-02 e RM-05, apresentou o predomínio de fitoclastos opacos bioestruturados (36-50\%), MOA e/ou fitoclastos não opacos estriados, típicos da vegetação de borda de planícies de inundação como componentes subordinados, além de esporos de fungos. No perfil P5 a palinofácies B representa a planície de inundação depositada há aproximadamente 5.529 anos A.P.

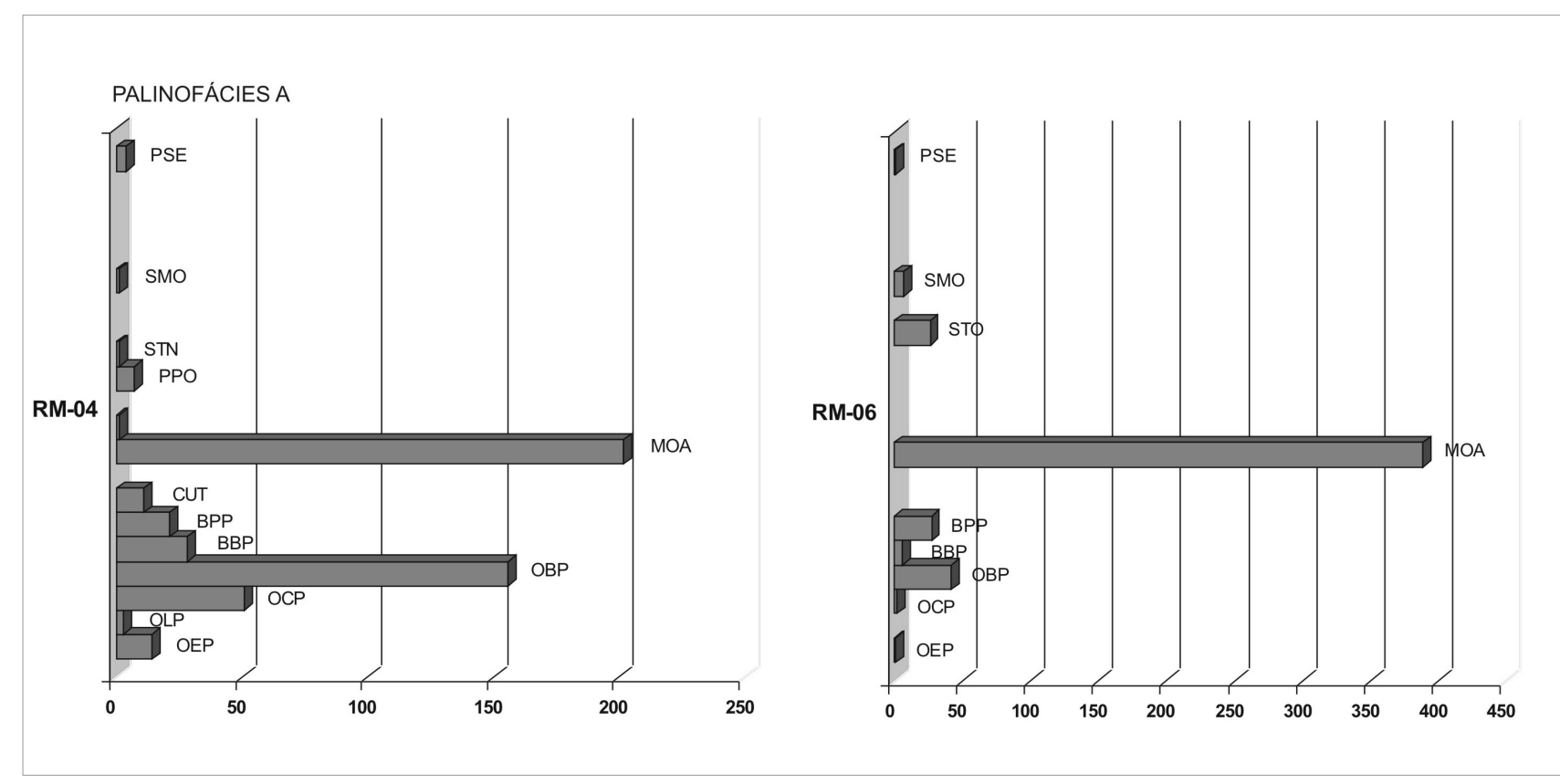

Figura 3. Frequência absoluta dos componentes da matéria orgânica particulada da palinofácies A (amostras RM-04 e RM-06). Abreviaturas: PSE, ovos de platelmintos; SMO, esporo monolete ornamentado; STO, esporo trilete ornamentado; STN, esporo trilete não ornamentado; MOA, matéria orgânica amorfa; CUT, cutículas; BPP, fitoclasto não opaco bioestruturado; BBP, fitoclasto não opaco bioestruturado estriado; OBP, fitoclasto opaco bioestruturado; OCP, fitoclasto opaco corroído; OLP, fitoclasto opaco alongado; OEP, fitoclasto opaco equidimensional.

Figure 3. Frequency of particulate organic matter from Palynofacies A (samples RM-04 and RM-06), Abbreviations: PSE, platelminte eggs; SMO, ornamented monolete spore; STO, ornamented trilete spore; STN, non-ornamented trilete spore; MOA, amorphous organic matter; CUT, cuticles; BPP, pitted bioestructured brown phytoclast; BBP, striate bioestructured brown phytoclast; OBP, opaque bioestructured phytoclast; OCP, corroded opaque phytoclast; OLP, opaque lath-shaped phytoclast; OEP, equant opaque phytoclast. 


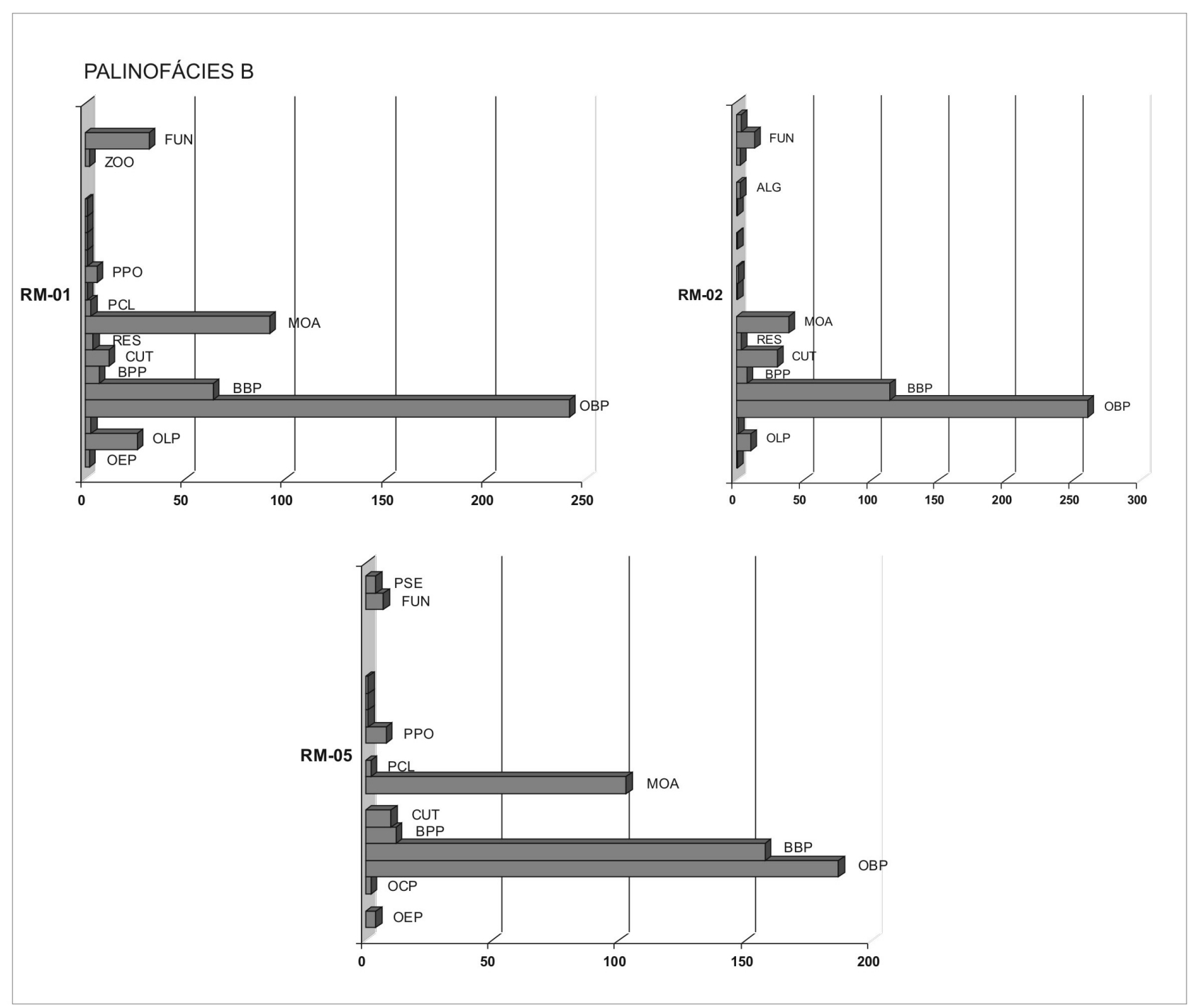

Figura 4. Frequência absoluta dos componentes da matéria orgânica particulada da Palinofácies $B$ (amostras RM-01, RM-02 e RM-05). Abreviaturas: FUN, esporos de fungos; ZOO, zooclastos; ALG, algas; PPO, grão de pólen porado; PCL, grão de pólen colpado; MOA, matéria orgânica amorfa; RES, resinas; CUT, cutículas; BPP, fitoclasto não-opaco bioestruturado; OBP, fitoclasto opaco bioestruturado; OLP, fitoclasto opaco alongado; OEP, fitoclasto opaco equidimensional.

Figure 4. Frequency of particulate organic matter from Palynofacies B (samples RM-01, RM-02 and RM-05). Abbreviations: FUN, fungal spores; ZOO, zooclasts; ALG, algae; PPO, porate pollen grain; PCL, colpate pollen grain; MOA, amorphous organic matter; RES, resins; CUT, cuticles; BPP, pitted bioestructured brown phytoclast; OBP, opaque bioestructured phytoclast; OLP, opaque lath-shaped phytoclast; OEP, equant opaque phytoclast.

\section{DISCUSSÃO}

\section{Distribuição da matéria orgânica particulada em ambientes fluviais}

As duas palinofácies, A e B, identificadas nas Figuras 34, são características de dois subambientes deposicionais na paleo-planície de inundação do ribeirão da Mata.

Análises de palinofácies em sedimentos de ambientes fluviais e deltaicos quaternários visando à reconstituição dos diferentes paleoambientes que caracterizam estes depósitos ainda são escassos (e.g. Lorente, 1990; Hart, 1994, Grill et al., 2002) e a falta de padronização da nomenclatura dos componentes orgânicos particulados dificulta a correlação entre os resultados obtidos nos diferentes trabalhos.
Lorente (1990), estudando a matéria orgânica particulada dos subambientes deposicionais do Alto Delta do Rio Orinoco na Venezuela, dividiu a matéria orgânica particulada contida nos depósitos das planícies de inundação em dois grupos que teriam sua deposição influenciada pelas estações seca e chuvosa. Os componentes orgânicos particulados depositados durante a estação chuvosa mostram uma matéria orgânica com brilho e colorida, com abundantes restos de fungos e partes de insetos, usualmente grossa com variabilidade grande na forma das partículas. A matéria orgânica das planícies de inundação expostas aos efeitos da estação seca se caracteriza por apresentar uma coloração preta com grânulos finos e pequenos, e, se encontra esparsamente distribuída. Quando comparados os resultados da caracterização da matéria 
orgânica particulada encontrados por Lorente (1990) com aqueles identificados nos depósitos da planície de inundação do ribeirão da Mata, pode-se estabelecer uma correlação da palinofácies influenciada pela estação chuvosa com a palinofácies A. Durante a estação chuvosa a lâmina d'água aumenta nestes depósitos, o que favorece a deposição da matéria orgânica por decantação. Assim, são verificadas condições disóxicas-anóxicas na lâmina d'água e/ou próximo da interface água/sedimento com predomínio de matéria orgânica amorfa. Já a matéria orgânica caracterizada por Lorente (1990) durante a estação seca, que tem como característica principal a coloração preta com grânulos finos e pequenos, não encontra correlação nos depósitos do ribeirão da Mata.

A palinofácies B, com predomínio de fitoclastos opacos bioestruturados e fitoclastos não-opacos estriados, pode representar as áreas de borda da planície de inundação, com a maior contribuição de fitoclastos não-opacos estriados advindos da vegetação paludal. No entanto, não se pode descartar uma maior influência de enchentes do canal fluvial depositando os fitoclastos nesta planície de inundação, já que as camadas de argila que caracterizam os depósitos da planície de inundação são intercaladas por camadas de siltito e areia fina.

Hart (1994) estudou os padrões de distribuição da matéria orgânica particulada em sedimentos de fundo dos diferentes ambientes deposicionais de um delta na região da Louisiana, nos Estados Unidos. Os resultados deste estudo mostraram que o principal componente orgânico particulado dos lagos da margem isolados da influência do canal fluvial, foi a MOA. A MOA também representa o principal componente orgânico particulado dos depósitos de planície de inundação da palinofácies A dos depósitos do ribeirão da Mata.

Grill et al. (2002) estudaram a sequência sedimentar holocênica de Rio Varela, no Canal de Beagle, Argentina. Os resultados obtidos neste estudo mostraram que na base da sequência, o ambiente marinho próximo da costa evoluiu a um ambiente marinho nerítico externo (palinofácies A e B) a lacustre continental (palinofácies $\mathrm{C}$ ), seguido de um ambiente pantanoso influenciado pelo aumento do nível do mar (palinofácies D), e condições fluviais/estuarinas (palinofácies E), seguido de ambiente fluvial (palinofácies F), para o topo da sequência, o solo atual (palinofácies G). Embora a evolução quaternária deste ambiente fluvial tenha sido diretamente influenciada pelas variações do nível relativo do mar é possível encontrar correlação da palinofácies F de Grill et al. (1994), característica dos depósitos de meandros abandonados, com as palinofácies A identificada no ribeirão da Mata. A palinofácies $\mathrm{F}$ do depósito de Rio Varela apresentou MOA (50-60\%) e fitoclastos opacos (10-20\%) como os componentes orgânicos particulados mais significativos.

\section{CONSIDERAÇÕES FINAIS}

Os perfis sedimentares que caracterizam a evolução holocênica do ribeirão da Mata evidenciaram sequências sedimentares constituídas pela sucessão de fácies de areia grossa com estratificação cruzada que caracterizam os depó- sitos do canal fluvial na base, sobrepostas por camadas de argila intercaladas por camadas de siltito e areia fina associadas aos depósitos de planície de inundação; seguidas de sedimentos mais grossos que constituem os paleocanais com indicações de paleocorrentes, e, no topo, pacotes de silte a areia fina com concreções ferruginosas, relacionadas ao sistema fluvial mais recente.

A matéria orgânica particulada recuperada das fácies identificadas nos perfis estratigráficos dos depósitos fluviais quaternários do ribeirão da Mata reflete o ambiente deposicional das paleoplanícies de inundação.

A palinofácies A (amostras RM-04 e RM-06) mostrou que a MOA foi o componente orgânico particulado mais significativo $(60 \%)$, seguida em menor representatividade pelos fitoclastos opacos bioestruturados $(20 \%)$ e pelos fitoclastos não-opacos (8\%). Esta palinofácies caracteriza as regiões com lâmina d'água mais profunda e disóxicas-anóxicas da paleoplanície de inundação, e foi representativa dos sedimentos depositados entre 7.258 e 5.529 anos A.P., no perfil P6.

Já a palinofácies B (amostras RM-01, RM-02 e RM-05) mostrou fitoclastos não-opacos estriados (36-50\%), típicos da vegetação de borda de planícies de inundação, MOA e/ ou fitoclastos não-opacos perfurados como componentes subordinados, além de esporos de fungo, e representa as áreas de borda da planície de inundação. No perfil P5, a palinofácies B representa a planície de inundação depositada há aproximadamente 5.529 anos A.P.

É importante ressaltar que nos dias de hoje a intensa atividade de mineração degradou completamente as áreas de planície de inundação e que este tipo de ambiente deposicional não se verifica mais ao longo das margens do ribeirão da Mata. Dessa forma, os resultados obtidos neste trabalho são significativos no contexto da sedimentação da matéria orgânica particulada e constituem importante parâmetro na interpretação dos paleoambientes fluviais com influência antrópica durante o Quaternário.

\section{AGRADECIMENTOS}

Este trabalho foi realizado no âmbito do projeto "Geohazards and Georesources in the northern periphery of Belo Horizonte - $M G$ ", desenvolvido em parceria entre a UFMG e a Universidade Técnica de Darmstadt (Alemanha), com recursos do Deutscher Akademischer Austauschdienst (DAAD). O segundo autor agradece a Fundação de Amparo à Pesquisa do Estado de Minas Gerais (FAPEMIG) e ao Conselho Nacional de Desenvolvimento Científico e Tecnológico $(\mathrm{CNPq})$, pela concessão de bolsa. Os autores agradecem a Maria Judite Garcia e ao revisor anônimo pelas sugestões que muito enriqueceram este trabalho. Contribuição apresentada no XII SBPP (Florianópolis, 02 a 05 de novembro de 2008).

\section{REFERÊNCIAS}

Almeida, F.F.M. 1977. O Cráton do São Francisco. Revista Brasileira de Geociências, 7:285-295. 
Alkmim, F.F. \& Martins-Neto, M.A. 2001. A Bacia Intracratônica do São Francisco: arcabouço estrutural e cenários evolutivos. In: M.A. Martins-Neto \& C.P. Pinto (eds.) A Bacia do São Francisco - geologia e recursos naturais, SBG/MG, p. 9-30.

Büchi, A. \& Pagung, R. 2008. Mapeamento geológico (1:25.000), neotectônica e georecursos da região de Vespasiano e São José da Lapa - MG. Curso de Geologia, Universidade Federal de Minas Gerais, Trabalho de Graduação, 80 p.

Dorr, J.V.N. 1969. Physiographic stratigraphic and structural development of the Quadrilatero Ferrífero, Minas Gerais, Brazil. Washington, DNPM/USGS, 109 p. (Prof. Paper 641A).

Hart , G.F. 1986. Origin and classification of organic matter in clastic systems. Palynology, 10:1-23.

Hart, G. 1994. Maceral palynofacies of the Louisiana deltaic plain in terms of organic constituents and hydrocarbon potential. In: A. Traverse (ed.) Sedimentation of organic particles, Cambridge University Press, p. 141-197.

Hofmann, M.; Büchi, A.; Hoppe, A.; Hornung, J.; Karfunkel, J. \& Pagung, R. 2009. Resources for a growing city - sand extraction north of Belo Horizonte (Brazil). Neues Jahrbuch für Geologie und Paläontologie Abhandlungen, 253:61-78.

Grill, S.; Borromei, A.M.; Quattrocchio, M.; Coronato, A.; Bujalesky, G. \& Rabassa, J. 2002. Palynological and sedimentological analysis of Recent sediments from Rio Varela, Beagle Channel, Tierra del Fuego, Argentina. Revista Española de Micropaleontología, 34(2):145-161.

Karfunkel, J.; Aranha, P.R.A.; Büchi, A.; Pimenta, F.; Pagung, R.;Silva Pinto, J.A.; Hofmann, M., \& Hoppe, A. 2006. Registros neotectônicos entre Vespasiano e Pedro Leopoldo ao norte de Belo Horizonte, Minas Gerais. In: CONGRESSO BRASILEIRO DE GEOLOGIA, 42, 2006. Boletim de Resumos, Aracaju, SBG, p. 292.

Kohler, H.C.1989. Geomorfologia cárstica na região de Lagoa Santa, MG. Instituto de Geociências, Universidade de São Paulo, Tese de Doutorado, 113 p.

Lenoir, E.A. \& Hart, G. 1988. Palynofacies of some Miocene sands from the Gulf of Mexico, offshore Louisiana, USA. Palynology, 12:151-165.

Lorente, M. 1990. Textural characteristics of organic matter in several subenvironments of the Orinoco Upper Delta. Geologie en Mijnbouw, 69:263-278.

Mendonça Filho, J.G. 1999. Aplicação de estudos de palinofácies e fácies orgânica em rochas do Paleozóico da Bacia do Paraná, Sul do Brasil. Programa de Pós-Graduação em Geociências, Universidade Federal do Rio Grande do Sul, Tese de Doutorado, $338 \mathrm{p}$.
Mendonça Filho, J.G.; Carvalho, M.A. \& Menezes, T.R. 2002. Palinofácies: In: T.L. Dutra (org.) Técnicas e procedimentos de trabalho com fósseis e formas modernas comparativas, Editora Unisinos, p. 20-24.

Menezes, T. R. 2002. Aplicação de parâmetros palinofaciológicos e organogeoquímicos na reconstrução paleoambiental do talude continental brasileiro recente na Bacia de Campos, RJ. Programa de Pós-Graduação em Geologia, Universidade Federal do Rio de Janeiro, Dissertação de Mestrado, 174 p.

Menezes, T.R.; Mendonça Filho, J.G.; Araújo, M.C.; Souza, I.V.A.F. \& Mendonça, J.O. 2008. Fácies orgânica: conceitos, métodos e estudos de casos na indústria do petróleo. Revista Brasileira de Geociências, 38(2-suplemento):1-17.

Meyer, K.E.B.; Mendonça Filho, J.G.; Ashraf, A.R.; Souza, P.A. \& Reichhart, K. 2005. Análise de palinofácies em sedimentos holocênicos da lagoa dos Quadros, Rio Grande do Sul, Brasil. Revista Brasileira de Paleontologia, 8(1):57-72.

Meyer, K.E.B.; Souza, P.A.; Cwik, M.R.; Menezes, T.R. \& Buchmann, F.S. 2006. Palinofácies e processos deposicionais em sedimentos de fundo da lagoa dos Quadros, planície costeira do Rio Grande do Sul, Brasil. Revista Brasileira de Geociências, 36(4):569-576.

Nimer, E. 1989. Climatologia do Brasil. Rio de Janeiro, Fundação Instituto Brasileiro de Geografia e Estatística, 421 p.

Noce, C.M.; Teixeira, W. \& Machado, N. 1997. Geoquímica dos gnaisses TTGs e granitóides neoarqueanos do Complexo Belo Horizonte, Quadrilátero Ferrífero, Minas Gerais. Revista Brasileira de Geociências, 27:25-32.

Pagung, R.; Pimenta, F.; Karfunkel, J.; Aranha, P.R.A.; Büchi, A.; Hofmann, M. \& Hoppe, A. 2007. Investigação de feições neotectônicas em Vespasiano-MG utilizando o georadar (GPR). In: SIMPÓSIO DE GEOLOGIA DO SUDESTE, 10, 2007. Boletim de Resumos, Diamantina, SBG/MG, p. 105.

Schöll, W.U. 1976. Sedimentologia e geoquímica do Grupo Bambuí, na parte sudeste da Bacia do São Francisco. In: CONGRESSO BRASILEIRO DE GEOLOGIA, 29, 1976. Anais, Ouro Preto, SBG, p. 207-231.

Suguio, K. 2003. Geologia sedimentar. São Paulo, Editora Edgard Blücher, $400 \mathrm{p}$.

Traverse, A. 1994. Sedimentation of palynomorphs and palynodebris: an introduction. In: A. Traverse (ed.) Sedimentation of organic particles, Cambridge University Press, p. $1-8$.

Tyson, R.V. 1995. Sedimentary organic matter: organic facies and palynofacies analysis. Londres, Chapman \& Hall, 615 p.

Received in January, 2009; accepted in February, 2010. 